\title{
BMJ Open Gender disparities in red blood cell transfusion in elective surgery: a post hoc multicentre cohort study
}

\author{
Hans Gombotz, ${ }^{1,2}$ Günter Schreier, ${ }^{2}$ Sandra Neubauer, ${ }^{2}$ Peter Kastner, ${ }^{2}$ \\ Axel Hofmann ${ }^{3,4,5}$
}

To cite: Gombotz H,

Schreier G, Neubauer S, et al. Gender disparities in red blood cell transfusion in elective surgery: a post hoc multicentre cohort study. BMJ Open 2016;6:e012210. doi:10.1136/bmjopen-2016012210

- Prepublication history for this paper is available online. To view these files please visit the journal online (http://dx.doi.org/10.1136/ bmjopen-2016-012210)

Received 11 April 2016 Revised 12 October 2016 Accepted 18 October 2016

CrossMark

For numbered affiliations see end of article.

Correspondence to Dr Hans Gombotz; hans.gombotz@chello.at

\section{ABSTRACT}

Objectives: A post hoc gender comparison of transfusion-related modifiable risk factors among patients undergoing elective surgery.

Settings: 23 Austrian centres randomly selected and stratified by region and level of care.

Participants: We consecutively enrolled in total 6530 patients (3465 women and 3065 men); 1491 underwent coronary artery bypass graft (CABG) surgery, 2570 primary unilateral total hip replacement (THR) and 2469 primary unilateral total knee replacement (TKR).

Main outcome measures: Primary outcome measures were the number of allogeneic and autologous red blood cell (RBC) units transfused (postoperative day 5 included) and differences in intraoperative and postoperative transfusion rate between men and women. Secondary outcomes included perioperative blood loss in transfused and non-transfused patients, volume of RBCs transfused, perioperative haemoglobin values and circulating red blood volume on postoperative day 5 .

Results: In all surgical groups, the transfusion rate was significantly higher in women than in men (CABG 81 vs $49 \%$, THR 46 vs $24 \%$ and TKR 37 vs $23 \%$ ). In transfused patients, the absolute blood loss was higher among men in all surgical categories while the relative blood loss was higher among women in the CABG group (52.8 vs $47.8 \%$ ) but comparable in orthopaedic surgery. The relative RBC volume transfused was significantly higher among women in all categories (CABG 40.0 vs 22.3; TKR 25.2 vs 20.2; THR 26.4 vs $20.8 \%$ ). On postoperative day 5 , the relative haemoglobin values and the relative circulating RBC volume were higher in women in all surgical categories. Conclusions: The higher transfusion rate and volume in women when compared with men in elective surgery can be explained by clinicians applying the same absolute transfusion thresholds irrespective of a patient's gender. This, together with the common use of a liberal transfusion strategy, leads to further overtransfusion in women.

\section{INTRODUCTION}

Women tend to live longer than men, but typically experience more stress, poorer

\section{Strengths and limitations of this study}

- It is a post hoc analysis using prospectively collected data from two similar and consecutive benchmark studies, including 6530 patients undergoing elective surgery in 23 centres.

- The main focus was the gender differences in the transfusion-related modifiable risk factors such as anaemia, blood loss and transfusion of red blood cells (triad of adverse outcome).

- Comparing absolute transfusion-related data and relative values in relation to the WHO's cut-off values enabled a fair gender comparison with baseline differences between men and women being eliminated.

- Perioperative blood loss, including the so-called hidden blood loss, and red blood cell volume transfused were precisely calculated.

- Owing to the observational character of the two benchmark studies, only routine parameters could be collected. As a consequence, several aspects of interest such as the causes of preoperative anaemia, cardiac comorbidities and data on transfusion outcomes could not be investigated.

health and more years with disabilities along the way. ${ }^{1}{ }^{2}$ Furthermore, in clinical decisionmaking and therapeutic interventions, gender disparities are common. Women are less likely to receive coronary angiography and coronary interventions, ${ }^{3-5}$ implantable cardioverter defibrillators, ${ }^{6}$ dialysis and renal transplants $^{7} 8$ or arthroplasties. ${ }^{9}$ Also, after surgical treatment, women have a higher risk for adverse outcomes and death, which may be at least partially attributable to a higher allogeneic transfusion rate. ${ }^{9-13}$

It is a matter of fact that women have a higher bleeding tendency ${ }^{14} 15$ and are more likely to be transfused than men. ${ }^{11-13}{ }^{16-21}$ The latter phenomenon, together with the occurrence of perioperative blood loss and anaemia, may worsen their postoperative outcome. However, in contrast to other 
preoperative risk factors, these factors can be mitigated by adequate and timely prevention and treatment.

In the last few years, the modern concept of patient blood management has been developed by international experts and implemented worldwide. ${ }^{22}{ }^{23}$ Its aim is to manage and preserve a patient's own blood by reducing the above-mentioned transfusion-related risk factorsanaemia, blood loss and red blood cell (RBC) transfusion - with the ultimate goal of improving the patient's outcome and safety. ${ }^{24}$ Therefore, identifying the underlying causes of the higher RBC transfusion rate in women and-as a consequence-enabling adequate and timely prevention and treatment might be of critical importance.

The aim of our study was a gender comparison in tion to differences in transfusion-related modifiable risk factors for an adverse outcome. ${ }^{24}$

\section{METHODS}

The present analysis included data from patients enrolled in two Austrian benchmark studies on blood use in elective surgery. ${ }^{20}{ }^{21}$ Both studies were prospective, observational multicentre studies with 23 participating centres, which were randomly selected and stratified by region and level of care. The study design, selection and recruitment of the centres, patient selection, data collection, quality management and first-line data analysis were similar in the two studies. The first study was conducted from April 2004 to February 2005, and the second study from July 2009 to August 2010. The present post hoc analysis was conducted without funding (whereas the original two studies on which the post hoc analysis is based were exclusively funded by the Austrian Ministry of Health).

In the two studies, we collected data from patients undergoing primary unilateral cemented or noncemented total hip replacement (THR), primary unilateral non-cemented total knee replacement (TKR) or coronary artery bypass graft (CABG) surgery. Based on the patients undergoing elective surgery with special atten-

Austrian Data Protection Commission's review, informed consent from individual patients was not necessary because only deidentified data were collected and complete patient confidentiality was maintained. After obtaining approval from the local ethics committee (Ethikkomission des Landes Oberösterreich, 15 July 2009), we consecutively enrolled all eligible patients aged 18 years or older. Our exclusion criteria were any other concomitant surgery, emergency surgery and an underlying coagulopathy documented by a history of bleeding and/or laboratory testing (international normalised ratio $>1.5$ or activated partial thromboplastin time $>35 \mathrm{~s}$ ).

Primary outcome measures were the number of intraoperatively and postoperatively allogeneic and autologous RBC units transfused and differences in transfusion rate between men and women (until postoperative day 5). Secondary outcomes included perioperative blood loss in transfused and non-transfused patients, volume of RBCs transfused, perioperative haemoglobin values and circulating red blood volume on postoperative day 5 .

We collected the following demographic and clinical data from the hospital records: patient age, body weight and height, preoperative use of platelet inhibitors or anticoagulants, type of anaesthesia, duration of surgery, use of a cell saver and length of hospital stay. In addition, we obtained routinely measured perioperative haemoglobin and haematocrit values and the number of RBC concentrates transfused. To account for gender differences, we presented the haemoglobin values as percentages of the anaemia cut-off values given by the WHO (figure 1). Comparing absolute transfusion-related data and relative values in relation to the WHO's cut-off values (WHO; women $120 \mathrm{~g} / \mathrm{L}$ and men $130 \mathrm{~g} / \mathrm{L})^{25}$ enabled a fair gender comparison with baseline differences between men and women being eliminated.

The body surface area was calculated using the Du Bois formula. ${ }^{26}$ The Nadler $e t a l^{27}$ formula was used to calculate the patients' blood volume. The total RBC volume was derived by multiplying the calculated blood volume with the corresponding haematocrit level. A

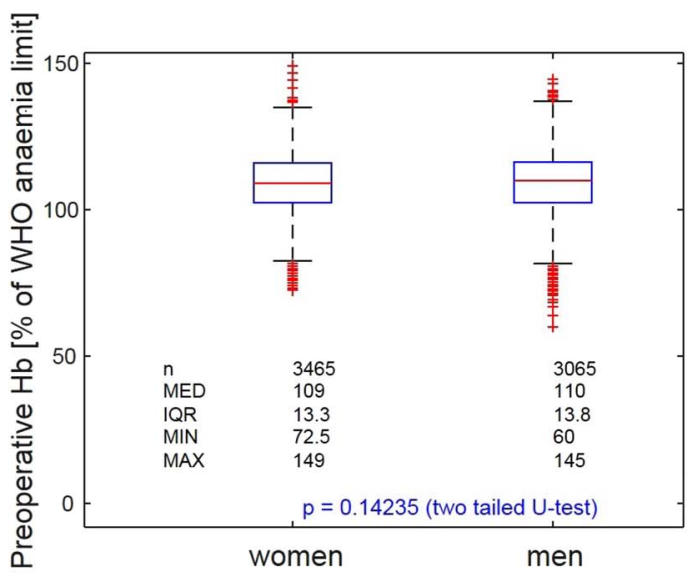

Figure 1 Boxplots for absolute versus relative haemoglobin values. The significant gender difference in haemoglobin values (left) disappears by using relative values according the WHO guidelines ${ }^{25}$ (right). Hb, haemoglobin. 
factor of 0.91 was applied to correct the haematocrit value for peripheral blood sampling. ${ }^{28}$ The overall perioperative RBC loss was calculated by subtracting the $\mathrm{RBC}$ volume on postoperative day 5 from the preoperative $\mathrm{RBC}$ volume and by adding the total RBC volume transfused. Differences in the average haematocrit (range 56-65\%) and volume (range 250-316.7 mL) of RBC units from different blood banks were accounted for by multiplying the volume by the mean haematocrit of the respective unit. To calculate the salvaged, washed and returned RBC volume during cell saver use, we assumed a haematocrit level of $60 \% .^{29}$ To adjust for baseline differences in the total RBC volume, the lost and transfused RBC volumes were analysed as percentages of the patient's total circulating baseline RBC volume (relative RBC volume).

We provided a web-based electronic data capture system for data acquisition with a training programme included. During the initiation visit, the study physicians -mainly members of anaesthesia departments-received special training on the system. Data were recorded directly into the study database. The system provided login names and passwords dedicated for registration of patients, monitoring of recruiting progress, query management and source data verification, as well as an internal communication platform. Automatic data entry plausibility checks and mandatory data items enforced high data quality and completeness. On-site Contract Research Organisation (CRO) monitoring on a regular basis (at least twice during the study period per centre) was performed with special focus on continuity of enrolment and patient selection criteria. ${ }^{21}$

Descriptive statistics for the data were presented as median and IQR, or absolute and relative frequencies $(\%)$. Differences between women and men were tested for statistical significance using the Mann-Whitney $U$ test for continuous variables and the $\chi^{2}$ test for frequencies, respectively.

Multivariate analysis was already performed in the two previous studies using logistic regression with RBC transfusion and multiple linear regression analysis with the relative volume of RBCs transfused (relative to the patient's estimated RBC volume) as the dependent variables. The independent variables included age, sex, body mass index (BMI), American Society of Anaesthesiology (ASA) physical status classification score, preoperative and lowest perioperative haemoglobin, type of anaesthesia, duration of surgery, usage of intraoperative cell salvage, infusion of washed versus unwashed shed blood, treatment with platelet (PLT) aggregation inhibitors and relative lost RBC volume. In CABG procedures, the number of bypasses, use of extracorporeal circulation and use of tranexamic acid were additional independent variables. Given the nature of the study, no formal sample size estimation was deemed necessary. ${ }^{20} 21$ In the current study, however, we conducted additional multivariate analyses on gender disparity and found only negligible differences.

We used Matlab, release 2015a (The MathWorks, Natick, Massachusetts, USA) for the statistical analysis. Box plots, bar charts and line diagrams were used to present the data graphically. A value of $p<0.05$ was considered to indicate statistical significance.

\section{Minimising the risk of bias}

Participating centres were randomly selected and stratified by region and level of care. Patients in each centre were enrolled consecutively. To ensure correct enrolment and adherence to patient selection criteria, onsite monitoring was regularly performed (twice per centre). During the initiation visit, the study physicians-mainly members of anaesthesia departments-received special training on the remote data entry system. Data were recorded directly into the study database.

Comparing absolute transfusion-related data and relative values in relation to the WHO's cut-off values enabled a fair gender comparison with baseline differences between men and women being eliminated. Differences in the average haematocrit and volume of RBC units from different blood banks were accounted for by multiplying the volume by the mean haematocrit of the respective blood bank.

\section{RESULTS}

\section{Patient characteristics and perioperative data}

The present analysis included 6530 patients (3465 women and 3065 men; table 1), with 1491 patients (350 women and 1141 men) undergoing CABG surgery, 2570 patients (1424 women and 1146 men) undergoing THR and 2469 patients (1691 women and 778 men) undergoing TKR. Table 2 gives an overview of the demographic characteristics and perioperative parameters. Men were younger (except for those undergoing TKR) and taller than women, and they had a higher body surface area and a higher body weight. There were no gender

\section{Table 1 Patients included}

\begin{tabular}{lccc}
\hline $\begin{array}{l}\text { Total=study } \\
\text { I+study II }\end{array}$ & Women & Men & Sum \\
\hline CABG & $350=207+143$ & $1141=570+571$ & $1491=777+714$ \\
THR & $1424=768+656$ & $1146=579+567$ & $2057=1347+1223$ \\
TKR & $1691=891+800$ & $778=351+427$ & $2469=1242+1227$ \\
Sum & $3465=1866+1599$ & $3065=1500+1565$ & $6530=3366+3164$ \\
\hline CABG, coronary artery bypass graft; THR, total hip replacement; TKR, total knee replacement. &
\end{tabular}


Table 2 Demographic data

\begin{tabular}{|c|c|c|c|}
\hline & Women & Men & p Value \\
\hline \multicolumn{4}{|l|}{ Age } \\
\hline All & $70 / 14$ & $67 / 14$ & $<0.000$ \\
\hline CABG & $71 / 13$ & $66 / 13$ & $<0.0001$ \\
\hline THR & $69 / 15$ & $66 / 15$ & $<0.000$ \\
\hline TKR & $71 / 12$ & $70 / 12$ & 0.0017 \\
\hline \multicolumn{4}{|c|}{ Body weight $(\mathrm{kg})$} \\
\hline All & $74 / 19$ & $84 / 18$ & $<0.000$ \\
\hline CABG & $70 / 16$ & $82 / 18$ & $<0.000$ \\
\hline THR & $72 / 17$ & $84 / 19$ & $<0.000$ \\
\hline TKR & $78 / 20$ & $87 / 18$ & $<0.000$ \\
\hline \multicolumn{4}{|c|}{ Body height $\left(\mathrm{m}^{2}\right)$} \\
\hline All & $162 / 8$ & $174 / 9$ & $<0.000$ \\
\hline CABG & $160 / 9$ & $173 / 8$ & $<0.000$ \\
\hline THR & $162 / 9$ & $175 / 10$ & $<0.000$ \\
\hline TKR & $162 / 7$ & $174 / 8$ & $<0.000$ \\
\hline \multicolumn{4}{|l|}{ BSA $\left(m^{2}\right)$} \\
\hline All & $1.79 / 0.23$ & $1.99 / 0.23$ & $<0.000$ \\
\hline CABG & $1.74 / 0.22$ & $1.96 / 0.22$ & $<0.000$ \\
\hline THR & $1.77 / 0.22$ & $1.99 / 0.25$ & $<0.000$ \\
\hline TKR & $1.82 / 0.23$ & $2.02 / 0.24$ & $<0.000$ \\
\hline \multicolumn{4}{|c|}{ ASA score } \\
\hline All & $2 / 1$ & $3 / 1$ & $<0.000$ \\
\hline CABG & $3 / 0$ & $3 / 0$ & 0.233 \\
\hline THR & $2 / 1$ & $2 / 1$ & 0.700 \\
\hline TKR & $2 / 1$ & $2 / 1$ & 0.909 \\
\hline \multicolumn{4}{|c|}{ EuroSCORE } \\
\hline & $5 / 4$ & $4 / 3$ & $<0.00$ \\
\hline
\end{tabular}

Preoperative anaemia (number yes $(\%)$ )

$\begin{array}{llll}\text { All } & 629(18.2) & 582(19.0) & 0.3859 \\ \text { CABG } & 106(30.3) & 270(23.7) & \mathbf{0 . 0 1 2 6} \\ \text { THR } & \mathbf{2 4 3 ( 1 7 . 1 )} & \mathbf{1 7 3}(\mathbf{1 5 . 1}) & \mathbf{0 . 1 7 8 0} \\ \text { TKR } & 280(16.6) & 139(17.9) & 0.4212\end{array}$

Platelet inhibitors (preoperative) (number yes (\%))

$\begin{array}{llll}\text { All } & 332(9.6) & 730(23.8) & <0.0001 \\ \text { CABG } & 159(45.4) & 567(49.7) & 0.1626 \\ \text { THR } & 70(4.9) & 87(7.6) & \mathbf{0 . 0 0 4 9}\end{array}$

TKR $\quad 103(6.1) \quad 76(9.8)$

Regional anaesthesia (number yes (\%))

$\begin{array}{lllr}\text { All } & 1777(51.3) & 1140(37.2) & <0.0001 \\ \text { THR } & 777(54.6) & 649(56.6) & 0.2946 \\ \text { TKR } & 1000(59.1) & 490(63.0) & 0.0696\end{array}$

Minimal invasive surgery (number yes (\%))

$\begin{array}{llll}\text { All } & 59(1.70) & 71(2.32) & 0.0764 \\ \text { CABG } & 2(0.57) & 14(1.23) & 0.2977 \\ \text { THR } & 56(3.93) & 56(4.89) & 0.2390 \\ \text { TKR } & 1(0.06) & 1(0.13) & 0.5734\end{array}$

Duration of surgery (min)

$\begin{array}{lllr}\text { All } & 80 / 45 & 105 / 122 & <0.0001 \\ \text { CABG } & 216 / 92 & 220 / 97 & 0.4573 \\ \text { THR } & 70 / 32 & 72 / 30 & \mathbf{0 . 0 0 1 2} \\ \text { TKR } & 84 / 39 & 90 / 46 & <\mathbf{0 . 0 0 0 1}\end{array}$

Duration of extracorporeal circulation ( $\mathrm{min}$ )

$\begin{array}{llll}\text { CABG } & 88 / 39 & 90 / 44 & 0.458\end{array}$

Use of aprotinin or tranexamic acid* (number yes $(\%)$ )

$$
\begin{array}{llll}
\text { CABG } & 336(96) & 1103(96.7) & 0.5503
\end{array}
$$

Use of cell saver (number yes (\%))

\begin{tabular}{llll} 
All & $1694(48.9)$ & $1478(48.2)$ & 0.5904 \\
CABG & $152(43.4)$ & $504(44.2)$ & 0.8064 \\
\hline
\end{tabular}

Continued
Table 2 Continued

\begin{tabular}{cllr}
\hline & Women & Men & p Value \\
\hline THR & $750(52.7)$ & $589(51.4)$ & 0.5210 \\
TKR & $792(46.8)$ & $385(49.5)$ & 0.2207 \\
Length of stay (days) & & \\
All & $12 / 4$ & $11 / 4$ & $<0.0001$ \\
CABG & $10 / 6$ & $10 / 5$ & 0.1753 \\
THR & $12 / 4$ & $11 / 3$ & $<\mathbf{0 . 0 0 0 1}$ \\
TKR & $12 / 3$ & $12 / 4$ & $\mathbf{0 . 0 0 1 5}$
\end{tabular}

Bold values indicate $p$ Values $<0.05$.

Values are presented as median/IQR for non-normally distributed

variables, or number (\%) for categorical variables.

The percentages are calculated based on the total applicable population for each variable.

Presented $p$ values correspond to Mann-Whitney $U$ test, or $\chi^{2}$ test, respectively.

*Aprotinin was used in the first study and tranexamic acid was used in the second study only.

ASA, American Society of Anaesthesiology; CABG, coronary artery bypass graft; THR, total hip replacement; TKR, total knee replacement.

differences in the BMI and the patients' overall health (American Society of Anaesthesiologists score). Women in the CABG group also had a significantly higher surgical risk of death (euroSCORE) than men. Tranexamic acid was the main antifibrinolytic agent used in the second benchmark study, and aprotinin was the one used in the first benchmark study. The prevalence of anaemia was also similar in both genders with the exception of patients undergoing CABG surgery; in this subgroup, preoperative anaemia was more common among women than among men (prevalence in women, 30.3\% and prevalence in men, 23.7\%). In younger patients below the age of 60 , anaemia was more common in women, whereas at ages 70 years and older, anaemia was more common in men.

\section{Primary outcome variables}

In all subgroups, the transfusion rate was significantly higher in women than in men (CABG $81 \%$ vs $49 \%$, THR $46 \%$ vs $24 \%$ and TKR $37 \%$ vs $23 \%$; figure 2 ). Also women received one or two RBC units more often than men (figure 3). Overall, the transfusion rates were significantly higher in patients with preoperative anaemia than in those with non-anaemia (total population: women $75 \%$ vs $38 \%$, men $66 \%$ vs $25 \%$; CABG: women $93.4 \%$ vs $75.4 \%$, men $76.3 \%$ vs $40.0 \%$; THR: women $77.0 \%$ vs $37.8 \%$, men $60.7 \%$ vs $17.7 \%$; TKR: women $65.4 \%$ vs $31.5 \%$, men $51.8 \%$ vs $16.9 \%$ ). Figure $4 \mathrm{~A}$, B shows the percentages of the transfused patients for the different surgical interventions, for patients with (top) and for those without (bottom) preoperative anaemia. Compared with the first study, the overall percentage of transfused patients and the mean number of RBC units transfused in the second study decreased in THR and TKR, but remained relatively unchanged in CABG surgery. Among the patients who received transfusions, there was no difference in the RBC volume as well as the number of units 


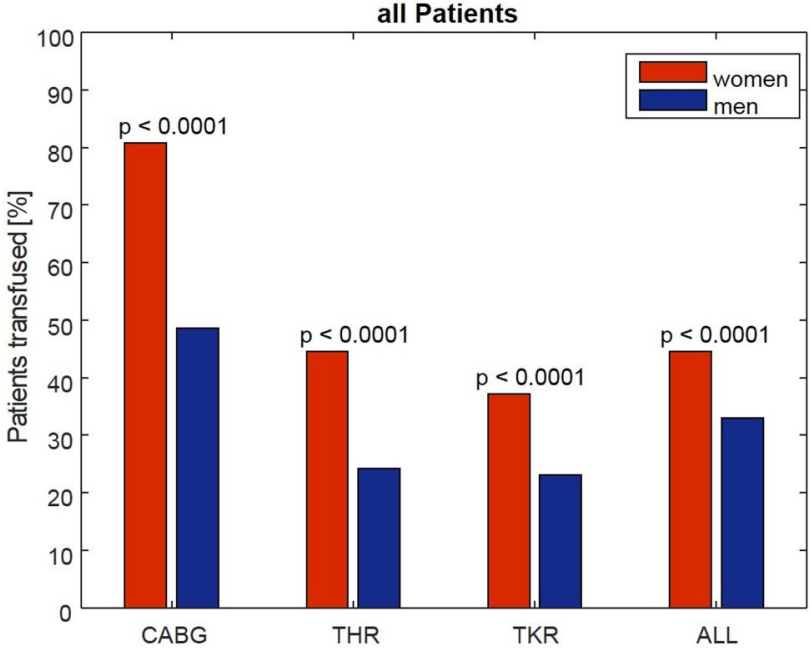

Figure 2 Type of surgery and percentage of patients transfused. CABG, coronary artery bypass graft; THR, total hip replacement; TKR, total knee replacement.

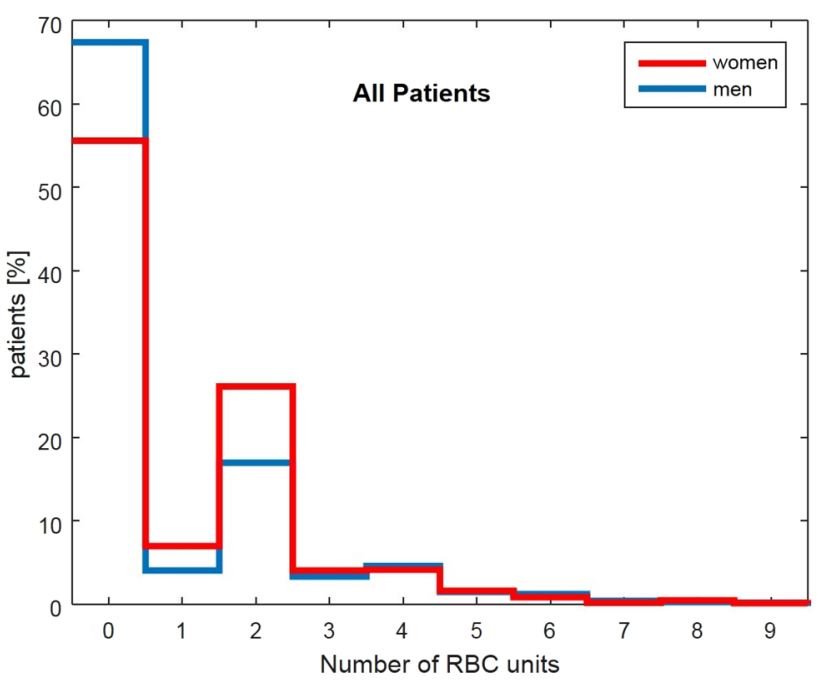

Figure 3 Percentage of patients receiving a given number of $\mathrm{RBC}$ units (indicating that women received one or two RBC units more often as men do, mostly at the expense of the percentage of patients who did not receive any transfusion. $\mathrm{RBC}$, red blood cell.

transfused between the studies. Usage of predonation of autologous blood in CABG procedures was negligible in the first $(0.5 \%)$ and second studies $(0.4 \%)$, and there was a substantial decrease of usage of predonation in orthopaedic patients from the first to the second study (THR, $11 \%$ to $4 \%$; TKR, $8-3 \%$, respectively).

\section{Secondary outcome variables}

The absolute blood loss among patients undergoing CABG was comparable in both genders, and that among patients undergoing orthopaedic surgery was slightly lower in women than in men. In contrast, the relative blood loss among patients undergoing CABG surgery was considerably higher in women than in men; it was
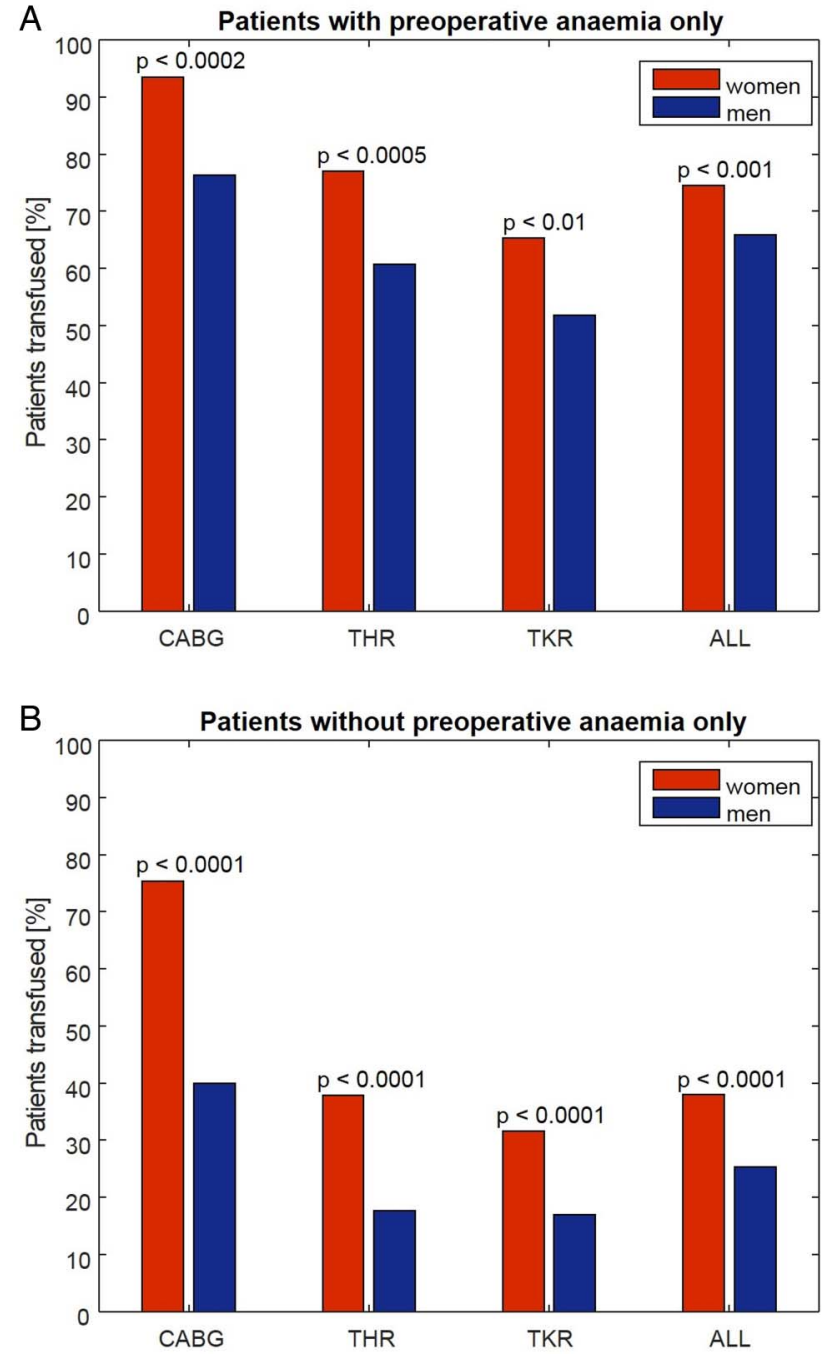

Figure 4 (A and $B)$ Transfusion rate in patients with anaemia (top) and non-anaemia (bottom). CABG, coronary artery bypass graft; THR, total hip replacement; TKR, total knee replacement.

also slightly higher in women in the THR group, whereas it was similar in both genders in the TKR group. The absolute RBC volume transfused was higher in women than in men among patients undergoing CABG surgery and equal in both genders among orthopaedic patients, whereas the relative RBC volume transfused was twice as high in women compared with men in the CABG group, and it was also elevated in women undergoing orthopaedic surgery. On postoperative day 5, absolute circulating blood volumes were significantly higher in men whereas relative blood volumes were significantly higher in women in all categories (table 3).

In transfused patients, the absolute RBC loss was lower in women than in men in all surgical categories, but the relative RBC loss was higher in women than in men in CABG surgery $(52.8 \%$ vs $47.8 \%, \mathrm{p}<0.0001)$ and comparable in both genders in orthopaedic surgery. The absolute RBC volume transfused was slightly higher in men. However, the relative RBC volume transfused was significantly higher in women than in men $(26.4 \%$ vs $20.8 \%$; $\mathrm{p}<0.0001$; 
Table 3 Transfusion-related variables (all patients)

\begin{tabular}{|c|c|c|c|c|c|c|}
\hline & \multicolumn{3}{|c|}{ Absolute (g/L, mL) } & \multicolumn{3}{|l|}{ Relative (\%) } \\
\hline & Women & Men & p Value & Women & Men & p Value \\
\hline \multicolumn{7}{|c|}{ Hb preoperative (g/L) } \\
\hline All & $131 / 16$ & $143 / 18$ & $<0.0001$ & 109/13.3 & $110 / 13.8$ & 0.1424 \\
\hline CABG & $127 / 17$ & $141 / 20$ & $<0.0001$ & $105.83 / 14.17$ & $108.46 / 15.38$ & $<0.0001$ \\
\hline THR & $131 / 16$ & $144 / 16$ & $<0.0001$ & 109.17/13.33 & $110.77 / 12.31$ & 0.0004 \\
\hline TKR & $132 / 16$ & $143 / 18$ & $<0.0001$ & $110.00 / 13.33$ & $110.00 / 13.85$ & 0.8485 \\
\hline \multicolumn{7}{|c|}{ Hb POD5 (g/L) } \\
\hline All & $100 / 15$ & $105 / 1.8$ & $<0.0001$ & $83.3 / 12.5$ & $80.8 / 13.8$ & $<0.0001$ \\
\hline CABG & $104 / 17$ & $106 / 1.8$ & 0.2730 & $86.88 / 14.17$ & $81.15 / 13.85$ & $<0.0001$ \\
\hline THR & $100 / 15$ & $105 / 1.7$ & $<0.0001$ & $83.33 / 12.50$ & $80.96 / 13.08$ & $<0.0001$ \\
\hline TKR & $100 / 15$ & $103 / 1.9$ & $<0.0001$ & 83.33/12.71 & $79.23 / 14.62$ & $<0.0001$ \\
\hline \multicolumn{7}{|c|}{ Hb nadir ( $g / L)$} \\
\hline All & $97 / 16$ & $102 / 1.8$ & $<0.0001$ & $80.8 / 13.3$ & $78.5 / 13.8$ & $<0.0001$ \\
\hline CABG & $98 / 17$ & $99 / 16$ & 0.0729 & $81.67 / 14.17$ & $76.15 / 12.31$ & $<0.0001$ \\
\hline THR & $97 / 15$ & $105 / 19$ & $<0.0001$ & $80.83 / 12.50$ & $80.77 / 14.62$ & 0.4955 \\
\hline TKR & $97 / 16$ & $102 / .0$ & $<0.0001$ & $80.83 / 13.33$ & $78.46 / 15.38$ & 0.0024 \\
\hline \multicolumn{7}{|c|}{ RBC volume preoperative } \\
\hline All & $1455 / 336$ & $2007 / 428$ & $<0.0001$ & - & - & - \\
\hline CABG & $1339 / 291$ & $1950 / 415$ & $<0.0001$ & - & - & - \\
\hline THR & $1435 / 319$ & $2037 / 435$ & $<0.0001$ & - & - & - \\
\hline TKR & $1494 / 343$ & $2028 / 434$ & $<0.0001$ & - & - & - \\
\hline \multicolumn{7}{|c|}{ RBC volume POD5 } \\
\hline All & $1127 / 267$ & $1477 / 352$ & $<0.0001$ & 76.6/13.2 & 74.3/13.0 & $<0.0001$ \\
\hline CABG & $1126 / 248$ & $1468 / 346$ & $<0.0001$ & $82.8 / 16.0$ & $75.4 / 14.0$ & $<0.0001$ \\
\hline THR & $1110 / 261$ & $1487 / 353$ & $<0.0001$ & $76.0 / 12.9$ & $73.4 / 12.5$ & $<0.0001$ \\
\hline TKR & $1148 / 289$ & $1477 / 366$ & $<0.0001$ & $76.0 / 12.6$ & $73.4 / 13.4$ & $<0.0001$ \\
\hline \multicolumn{7}{|c|}{ RBC volume lost } \\
\hline All & $488 / 290$ & $628 / 347$ & $<0.0001$ & $32.1 / 21.3$ & $30.7 / 17.2$ & $<0.0001$ \\
\hline CABG & $619 / 465$ & $655 / 438$ & 0.3945 & $46.5 / 36.3$ & $33.1 / 22.9$ & $<0.0001$ \\
\hline THR & $479 / 277$ & $620 / 311$ & $<0.0001$ & $32.4 / 20.9$ & 29.3/15.0 & $<0.0001$ \\
\hline TKR & $471 / 270$ & $615 / 296$ & $<0.0001$ & $30.2 / 18.2$ & $29.9 / 14.5$ & 0.1345 \\
\hline \multicolumn{7}{|c|}{ RBC units transfused (number yes (\%)) } \\
\hline All & $1545(44.6)$ & $1011(32.9)$ & $<0.0001$ & - & - & - \\
\hline CABG & $283(80.9)$ & $554(48.6)$ & $<0.0001$ & - & - & - \\
\hline THR & $634(44.5)$ & $277(24.2)$ & $<0.0001$ & - & - & - \\
\hline TKR & $628(37.1)$ & $180(23.1)$ & $<0.0001$ & - & - & - \\
\hline
\end{tabular}

Bold values indicate $p$ Values $<0.05$

Values are presented as median/IQR for measured values and frequencies (\%) for categorical variables.

The percentages are calculated as the fraction of the total applicable population for each variable.

CABG, coronary artery bypass graft; $\mathrm{Hb}$, haemoglobin; POD5, post-operative day 5; RBC, red blood cell; THR, total hip replacement; TKR,

total knee replacement.

table 4 and figure $5 \mathrm{~A}-\mathrm{C}$ ). The absolute preoperative RBC volume was $\sim 30 \%$ higher in men than in women, and the RBC volume on postoperative day 5 was $\sim 20 \%$ higher in men. On the other hand, on postoperative day 5 , the relative RBC volumes were elevated (by $\sim 5 \%$ ) in women in all surgical subgroups when compared with men.

In transfused patients, the absolute preoperative haemoglobin values were generally lower in women, and relative haemoglobin values were comparable except for the TKR subgroup. The lowest measured haemoglobin (nadir haemoglobin) value was slightly lower in women than in men in orthopaedic surgery, whereas the relative values were higher in women than in men among those undergoing CABG surgery. On postoperative day 5, the absolute haemoglobin values were slightly higher in men (except for CABG patients). In comparison, the relative haemoglobin values on postoperative day 5 were elevated in women in all surgical categories (table 4).

\section{Predictors of transfusion}

Apart from female sex, the relative lost RBC volume, relative preoperative haemoglobin and the lowest relative postoperative haemoglobin are strongest and independent predictors for RBC transfusion in all procedures (table 5). Regional anaesthesia was a significant factor in THR, ASA score was significant in TKR, and BMI and PLT inhibitors were significant predictors for transfusion in CABG.

First versus second study

Compared with the first study, in the second study the overall percentage of transfused patients and the mean number of RBC units transfused decreased in THR and 
Table 4 Transfusion-related variables (transfused patients only)

\begin{tabular}{|c|c|c|c|c|c|c|}
\hline & \multicolumn{3}{|c|}{ Absolute (g/L, mL) } & \multicolumn{3}{|c|}{ Relative (\%) } \\
\hline & Women & Men & p Value & Women & Men & p Value \\
\hline \multicolumn{7}{|c|}{$\mathrm{Hb}$ preoperative (only transfused patients) } \\
\hline All & $126 / 17$ & $134 / 19$ & $<0.0001$ & $105 / 14.2$ & $103 / 14.6$ & $<0.0001$ \\
\hline CABG & $124 / 17$ & $135 / 20$ & $<0.0001$ & $103 / 14.0$ & $104 / 15.4$ & 0.6925 \\
\hline THR & $126 / 17$ & $135 / 17$ & $<0.0001$ & $105 / 14.2$ & $104 / 13.3$ & 0.0120 \\
\hline TKR & $127 / 17$ & $133 / 20$ & $<0.0001$ & $106 / 14.2$ & $102 / 15.4$ & 0.0003 \\
\hline \multicolumn{7}{|c|}{ Hb POD5 (only transfused patients) } \\
\hline All & $102 / 17$ & $101 / 18$ & 0.9279 & $85.0 / 14.2$ & $77.7 / 13.7$ & $<0.0001$ \\
\hline CABG & $105 / 17$ & $102 / 18$ & 0.0485 & $87.5 / 14.0$ & $78.5 / 13.8$ & $<0.0001$ \\
\hline THR & $101 / 16$ & $101 / .9$ & 0.4562 & $84.2 / 13.3$ & $77.7 / 14.6$ & $<0.0001$ \\
\hline TKR & $101 / 16$ & $100 / 17$ & 0.4262 & $84.2 / 13.7$ & $76.9 / 13.1$ & $<0.0001$ \\
\hline \multicolumn{7}{|c|}{$\mathrm{Hb}$ nadir (only transfused patients) } \\
\hline All & $93 / 16$ & $94 / 16$ & 0.5446 & $77.5 / 13.3$ & $72.3 / 12.3$ & $<0.0001$ \\
\hline CABG & $97 / 18$ & $94 / 14$ & 0.0173 & $80.8 / 15.0$ & $72.3 / 10.8$ & $<0.0001$ \\
\hline THR & $93 / 15$ & $93 / 18$ & 0.4170 & $77.5 / 12.5$ & $71.5 / 13.8$ & $<0.0001$ \\
\hline TKR & $92 / 16$ & $93 / 16$ & 0.4918 & 76.7/13.3 & $71.5 / 12.3$ & $<0.0001$ \\
\hline \multicolumn{7}{|c|}{ RBC volume preoperative (only transfused patients) } \\
\hline All & $1370 / 290$ & $1830 / 398$ & $<0.0001$ & - & - & - \\
\hline CABG & $1320 / 256$ & $1830 / 405$ & $<0.0001$ & - & - & - \\
\hline THR & $1360 / 279$ & $1830 / 409$ & $<0.0001$ & - & - & - \\
\hline TKR & $1413 / 303$ & $1850 / 414$ & $<0.0001$ & - & - & - \\
\hline \multicolumn{7}{|c|}{ RBC volume POD5 (only transfused patients) } \\
\hline All & $1110 / 256$ & $1400 / 316$ & $<0.0001$ & $80.9 / 16$ & $76.9 / 15.7$ & $<0.0001$ \\
\hline CABG & $1120 / 243$ & $1410 / 314$ & $<0.0001$ & $84.4 / 16.4$ & $77.3 / 16.2$ & $<0.0001$ \\
\hline THR & $1090 / 252$ & $1390 / 347$ & $<0.0001$ & $80.2 / 15.6$ & $76.2 / 14.0$ & $<0.0001$ \\
\hline TKR & $1120 / 262$ & $1380 / 320$ & $<0.0001$ & $79.6 / 15.4$ & $77.6 / 16.5$ & $<0.0001$ \\
\hline \multicolumn{7}{|c|}{ RBC volume lost (only transfused patients) } \\
\hline All & $653 / 292$ & $871 / 441$ & $<0.0001$ & $47 / 18.9$ & $47.4 / 20.7$ & 0.9313 \\
\hline CABG & $703 / 415$ & $882 / 498$ & $<0.0001$ & $52.8 / 32.6$ & $47.8 / 24.1$ & 0.0001 \\
\hline THR & $635 / 280$ & $863 / 389$ & $<0.0001$ & $47.0 / 18.2$ & $47.1 / 17.4$ & 0.7359 \\
\hline TKR & $657 / 266$ & $869 / 415$ & $<0.0001$ & $45.9 / 15.8$ & $45.6 / 18.2$ & 0.7754 \\
\hline \multicolumn{7}{|c|}{ RBC volume transfused (only transfused patients) } \\
\hline All & $363 / 133$ & $365 / 284$ & $<0.0001$ & $26.4 / 14.7$ & $20.8 / 18.5$ & $<0.0001$ \\
\hline CABG & $539 / 417$ & $380 / 376$ & 0.0051 & $40.0 / 36.3$ & 22.3/22.9 & $<0.0001$ \\
\hline THR & $363 / 89.1$ & $363 / 219$ & 0.0041 & 26.3/12.2 & $20.1 / 11.4$ & $<0.0001$ \\
\hline TKR & $363 / 72.8$ & $363 / 144$ & 0.0226 & $25.2 / 10.8$ & $20.2 / 14.0$ & $<0.0001$ \\
\hline
\end{tabular}

TKR, but remained relatively unchanged in CABG surgery. Among the patients who received transfusions, there was no difference in the RBC volume and the number of units transfused between the studies.

Transfusion rate in THR procedures decreased in seven centres while it increased in one centre compared with the first study. Eight centres had decreased transfusion rates in TKR. In CABG, transfusion rate significantly increased in one centre and decreased in another centre compared with the first study. Usage of predonation of autologous blood in CABG procedures was negligible in the first $(0.5 \%)$ and second studies $(0.4 \%)$, and there was a substantial decrease of usage of predonation in orthopaedic patients from the first to the second study (THR, $11 \%$ to $4 \%$; TKR, $8 \%$ to $3 \%$, respectively). ${ }^{20} 21$

\section{DISCUSSION}

The present study identified a higher transfusion rate in women compared with men in three surgical categories. Other findings of this study are:

- Although the absolute perioperative blood loss was higher in men in all subgroups, the relative blood loss was comparable between the genders in orthopaedic surgery, and in the CABG subgroup, it was higher in women.

- Furthermore, the relative RBC volume transfused was significantly higher in women in all surgical categories, especially in CABG surgery.

- This was accompanied by a higher relative nadir haemoglobin value and a higher haemoglobin value on postoperative day 5 in women. 

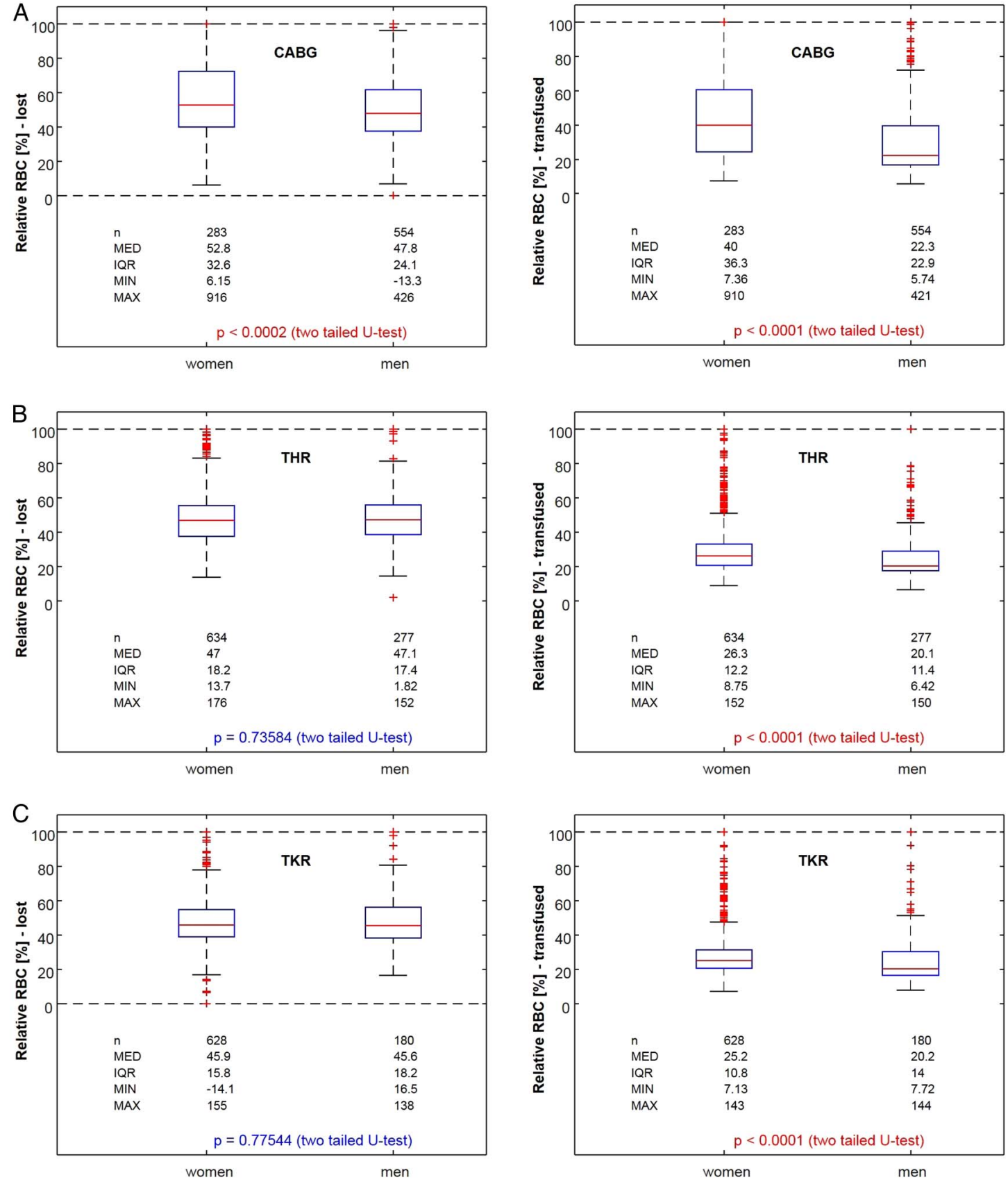

Figure 5 (A-C) Boxplots for absolute and relative RBC volumes: lost (left) and transfused (right) for CABG (top), THR (middle), TKR (bottom)-women versus men for transfused patients only. CABG, coronary artery bypass graft; RBC, red blood cell; THR, total hip replacement; TKR, total knee replacement.

- In addition, the calculated relative postoperative $\mathrm{RBC}$ volume in women was $\sim 5 \%$ higher than that in men across all surgical groups.

- There was no gender difference in the overall prevalence of preoperative anaemia as defined by the gender-specific WHO cut-off values.

Anaemia, blood loss and transfusion of RBCs constitute a triad of risk factors for adverse patient outcomes. ${ }^{24}{ }^{30-35}$ Each of these three parameters represents a risk factor in itself and their combination may further potentiate the risk of an adverse outcome. ${ }^{36}$ Within this triad, a vicious cycle is set in motion: blood loss and bleeding induce anaemia or exacerbate pre-existing anaemia. Anaemia triggers transfusion, and transfusionbesides having many other adverse effects-increases the risk of re-bleeding, potentially leading to additional blood loss, as shown in several studies. ${ }^{34}{ }^{37-40}$ The intention of breaking this vicious cycle by modifying these risk factors has led to the development of the concept of patient blood management, which is based on three pillars: optimisation of the patient's endogenous RBC mass; minimisation of diagnostic, interventional and surgical blood loss and optimisation of the patient's tolerance of anaemia. ${ }^{22} 41$ In most clinical scenarios, 
Table 5 Predictors of transfusion

\begin{tabular}{|c|c|c|c|c|c|c|}
\hline \multirow[b]{2}{*}{ Independent variable } & \multicolumn{2}{|l|}{ CABG } & \multicolumn{2}{|l|}{ THR } & \multicolumn{2}{|l|}{ TKR } \\
\hline & $\begin{array}{l}\text { Regression } \\
\text { coefficient }\end{array}$ & $\begin{array}{l}\text { OR } \\
\text { (95\% Cl) }\end{array}$ & $\begin{array}{l}\text { Regression } \\
\text { coefficient }\end{array}$ & $\begin{array}{l}\text { OR } \\
(95 \% \mathrm{Cl})\end{array}$ & $\begin{array}{l}\text { Regression } \\
\text { coefficient }\end{array}$ & $\begin{array}{l}\text { OR } \\
\text { (95\% Cl) }\end{array}$ \\
\hline \multicolumn{7}{|l|}{ Women } \\
\hline Preoperative $\mathrm{Hb}(\%)^{*}$ & -0.304 & $\begin{array}{l}0.74 \\
\text { (0.67 to } 0.83)\end{array}$ & -0.304 & $\begin{array}{l}0.74 \\
\text { (0.71 to } 0.77)\end{array}$ & -0.279 & $\begin{array}{l}0.76 \\
(0.73 \text { to } 0.79)\end{array}$ \\
\hline Lowest postoperative $\mathrm{Hb}(\%)^{\star}$ & 0.197 & $\begin{array}{l}1.22 \\
\text { (1.10 to } 1.35)\end{array}$ & 0.194 & $\begin{array}{l}1.22 \\
(1.17 \text { to } 1.26)\end{array}$ & 0.209 & $\begin{array}{l}1.23 \\
(1.19 \text { to } 1.28)\end{array}$ \\
\hline Lost RBC volume (\%)† & 0.402 & $\begin{array}{l}1.50 \\
(1.30 \text { to } 1.71)\end{array}$ & 0.405 & $\begin{array}{l}1.50 \\
(1.42 \text { to } 1.58)\end{array}$ & 0.437 & $\begin{array}{l}1.55 \\
\text { (1.47 to } 1.63)\end{array}$ \\
\hline Cases correctly classified (\%) & & 94.3 & & 93.5 & & 93.6 \\
\hline $\mathrm{R}^{2}$ & & 0.864 & & 0.857 & & 0.853 \\
\hline \multicolumn{7}{|l|}{ Men } \\
\hline Preoperative $\mathrm{Hb}(\%)^{\star}$ & -0.225 & $\begin{array}{l}0.80 \\
(0.77 \text { to } 0.83)\end{array}$ & -0.248 & $\begin{array}{l}0.78 \\
(0.74 \text { to } 0.82)\end{array}$ & -0.248 & $\begin{array}{l}0.78 \\
(0.74 \text { to } 0.82)\end{array}$ \\
\hline Lowest postoperative $\mathrm{Hb}(\%)^{\star}$ & 0.153 & $\begin{array}{l}1.17 \\
\text { (1.12 to } 1.21)\end{array}$ & 0.154 & $\begin{array}{l}1.17 \\
(1.12 \text { to } 1.22)\end{array}$ & 0.154 & $\begin{array}{l}1.17 \\
\text { (1.12 to } 1.22)\end{array}$ \\
\hline Lost RBC volume (\%)† & 0.301 & $\begin{array}{l}1.35 \\
(1.30 \text { to } 1.41)\end{array}$ & 0.359 & $\begin{array}{l}1.43 \\
\text { (1.34 to } 1.53)\end{array}$ & 0.359 & $\begin{array}{l}1.43 \\
\text { (1.34 to } 1.53)\end{array}$ \\
\hline Cases correctly classified (\%) & & 91.4 & & 94.7 & & 93.4 \\
\hline$R^{2}$ & & 0.800 & & 0.802 & & 0.786 \\
\hline
\end{tabular}

Percentage of the preoperatively circulating RBC volume.

Only significant predictors are presented.

*Percentages of the anaemia cut-off values given by the WHO (women $120 \mathrm{~g} / \mathrm{L}$ and men $130 \mathrm{~g} / \mathrm{L}$ ).

†Percentages of pre-operative RBC volume.

CABG, coronary artery bypass graft; $\mathrm{Hb}$, haemoglobin; RBC, red blood cell; THR, total hip replacement; TKR, total knee replacement.

application of just the first two pillars is sufficient to address all three risks of the triad. Optimisation of the RBC mass and the reduction of blood loss keep the haemoglobin levels of most patients above a level where transfusion might be considered. However, addition of the third pillar can further reduce transfusion rates. ${ }^{42}$

With regard to the optimisation of the patient's endogenous RBC mass (first pillar), women generally seem to be less susceptible to anaemia-induced adverse events than men. For example, in normal life, the lowest risk for mortality occurs at haemoglobin values between 130 and $150 \mathrm{~g} / \mathrm{L}$ in women and between 140 and $170 \mathrm{~g} / \mathrm{L}$ in men. ${ }^{43-46}$ In a cohort of 6880 elderly patients without severe comorbidities, mild and moderate anaemia was significantly associated with a higher mortality in men but not in women. ${ }^{32}{ }^{47}$ In a recent publication focusing on non-emergent CABG surgery, a low haematocrit and blood transfusion were significant predictors for major morbidity in men, whereas in women blood transfusion was the only predictor of major morbidity. ${ }^{32}$ In non-cardiac surgery, the mortality was higher in men than in women at similar haemoglobin levels.

The prevalence of preoperative anaemia in the present study was similar in both genders, so this factor cannot explain the higher transfusion rates in women. The fact that the prevalence of anaemia among women was similar to that among men might be attributable to the higher age of the patients included in the study, ${ }^{48}$ because the higher prevalence of low haemoglobin values observed in younger women disappears with increasing age. After the age of 75 years, men have, in fact, a higher prevalence of anaemia than women, with the prevalence among men being highest at age 85 years and older. ${ }^{49} 50$

The observation that anaemia is associated with a poor prognosis in many disorders is not a sufficient reason to assume a cause-and-effect relationship. Anaemia of chronic disease in particular may be associated with an adaptive physiological response. ${ }^{51} 52$ The treatment of mild-to-moderate anaemia of chronic disease may therefore not always bring the desired improvement or may even increase the mortality in some cases. ${ }^{53}$ Nevertheless, optimisation of the preoperative blood volume up to the WHO cut-off values should be an integral strategy to reduce the transfusion requirements in both genders. 5455

The amount of perioperative blood loss (second pillar) depends on the surgical technique, the management of perioperative coagulation and the blood conservation techniques used. The degree of acute blood loss that patients can safely tolerate is inversely related to their baseline haemoglobin concentration and the decrease of their RBC volume. ${ }^{56} \mathrm{~A}$ decrease of at least $50 \%$ from the preoperative haemoglobin level during cardiac surgery is associated with adverse outcomes even if the absolute haemoglobin level remains above the commonly used transfusion threshold of $7.0 \mathrm{~g} / \mathrm{dL}{ }^{57}$ 
In the present study, the absolute blood loss was smaller among women than among men in all surgical subgroups, but the relative perioperative blood loss was $5 \%$ higher among women than among men in the CABG subgroup, and it was comparable between men and women in the orthopaedic surgery subgroups. The higher blood loss among women undergoing CABG surgery may be attributable to the extreme haemodilution associated with extracorporeal circulation. As women have a lower BMI than men, their haemodilution during the operation is more profound, and women therefore tend to receive more transfusions during and after the CABG operation. ${ }^{18}$ Nevertheless, the differences in blood loss alone cannot explain why the RBC volume transfused among women was twice that among men in the CABG group and $25 \%$ higher than that among men in the orthopaedic surgery groups (table 4).

With regard to the tolerance of anaemia (third pillar), it is possible that the ability to compensate for low haemoglobin values differs by gender. Moreover, to the best of our knowledge, neither cut-off values nor transfusion guidelines exist for postmenopausal women. ${ }^{58} 59$ Several authors have suggested that anaemia in women beyond menopause should be defined by a higher haemoglobin threshold, similar to that used for men. ${ }^{44} 6061$ Current transfusion guidelines revolve around absolute haemoglobin values and do not account for this phenomenon, nor do they consider the special needs of women in general. ${ }^{59}{ }^{62-64}$ In fact, in routine clinical practice, similar transfusion triggers are applied in both genders. ${ }^{65}$

The present study has several limitations. First, it is a post hoc analysis that uses data from two similar consecutive benchmark studies. ${ }^{20}{ }^{21}$ Second, because financial resources were limited, postoperative outcomes could not be studied. Third, because of the observational character of the two benchmark studies, only routine parameters could be collected. Therefore, several aspects of interest such as the causes of preoperative anaemia could not be investigated.

A main strength of the study is the fact that the perioperative blood loss was calculated and the so-called hidden blood loss is therefore included in the analysis. Moreover, we compared absolute transfusion-related data and relative values (in relation to the WHO cut-off values). ${ }^{25}$ This enabled a fair gender comparison because baseline differences between men and women were eliminated.

The present findings-that women had a higher postoperative RBC volume in all surgical groups and higher intraoperative and postoperative haemoglobin levels, together with a higher relative RBC volume transfusedare clear indicators that the transfusion strategies applied in women were too liberal. These results could have a significant impact on blood usage levels and possibly lead to improvements in outcome and patient safety. Gender-specific transfusion thresholds and dosing are neither recommended by guidelines nor common in clinical practice. Therefore, the findings of this study might be generalisable across most transfused populations. Once clinicians are aware of the fact that women tend to be overtransfused, measures can be taken to address this matter. These include the correction of preoperative anaemia, the reduction of perioperative blood loss by optimising the surgical technique, the reduction of the transfusion volume (eg, by implementing a singleunit strategy) and the use of lower haemoglobin values as transfusion triggers. Such strategies may dramatically reduce the transfusion rate among women while improving outcome and patient safety.

\section{CONCLUSION}

The higher transfusion rate and volume in women, compared with men, in elective surgery can be explained by clinicians applying the same absolute transfusion thresholds irrespective of a patient's gender even though women have a lower baseline RBC volume. This, together with the common use of a liberal transfusion strategy in elective CABG and orthopaedic surgery despite the recommendations in relevant guidelines, leads to overtransfusion in women. Given the possibility to pre-empt transfusions through the treatment of modifiable risk factors by applying the patient blood management concept, a beneficial change in practice is warranted. Given the accumulating evidence on transfusion outcomes from meta-analyses of RCTs, ${ }^{66-69}$ comparing liberal versus restrictive transfusion thresholds, a prospective randomised controlled trial (RCT) comparing gender-specific transfusion thresholds and targets with current standard of care is warranted.

\section{Author affiliations}

${ }^{1}$ Department of Anaesthesiology and Intensive Care, General Hospital Linz, Vienna, Austria

${ }^{2}$ AlT Austrian Institute of Technology GmbH 8020, Graz, Austria

${ }^{3}$ Department of Anaesthesiology, University Hospital Zurich, Zurich, Switzerland

${ }^{4}$ Faculty of Medicine, School of Surgery, Dentistry and Health Sciences, University of Western Australia, Western Australia, Australia

${ }^{5}$ Faculty of Health Sciences, Curtin University, Western Australia, Australia

Contributors HG initiated and implemented both benchmark studies, designed data collection tools, and wrote and revised the paper. He is a guarantor. GS wrote the statistical analysis plan, analysed the data and revised the drafted paper. SN cleaned and analysed the data. PK monitored data collection for both trials, drafted and revised the paper. AH implemented both benchmark studies and revised the drafted paper.

Competing interests AH lectures for Vifor Pharma and TEM international.

Ethics approval Ethikkomission des Landes Oberösterreich, 15 July 2009

Provenance and peer review Not commissioned; externally peer reviewed.

Data sharing statement No additional data are available.

Open Access This is an Open Access article distributed in accordance with the Creative Commons Attribution Non Commercial (CC BY-NC 4.0) license, which permits others to distribute, remix, adapt, build upon this work noncommercially, and license their derivative works on different terms, provided the original work is properly cited and the use is non-commercial. See: http:// creativecommons.org/licenses/by-nc/4.0/ 


\section{REFERENCES}

1. Wang $\mathrm{H}$, Dwyer-Lindgren $\mathrm{L}$, Lofgren $\mathrm{KT}$, et al. Age-specific and sex-specific mortality in 187 countries, 1970-2010: a systematic analysis for the Global Burden of Disease Study 2010. Lancet 2012;380:2071-94.

2. Global Burden of Disease Study 2013 Collaborators. Global, regional, and national incidence, prevalence, and years lived with disability for 301 acute and chronic diseases and injuries in 188 countries, 1990-2013: a systematic analysis for the Global Burden of Disease Study 2013. Lancet 2015;386:743-800.

3. Blomkalns AL, Chen AY, Hochman JS, et al. Gender disparities in the diagnosis and treatment of non-ST-segment elevation acute coronary syndromes: large-scale observations from the CRUSADE (Can Rapid Risk Stratification of Unstable Angina Patients Suppress Adverse Outcomes With Early Implementation of the American College of Cardiology/American Heart Association Guidelines) National Quality Improvement Initiative. J Am Coll Cardiol 2005;45:832-7.

4. Tavris D, Shoaibi A, Chen AY, et al. Gender differences in the treatment of non-ST-segment elevation myocardial infarction. Clin Cardiol 2010;33:99-103.

5. Gnavi R, Rusciani R, Dalmasso M, et al. Gender, socioeconomic position, revascularization procedures and mortality in patients presenting with STEMI and NSTEMI in the era of primary $\mathrm{PCl}$. Differences or inequities? Int J Cardiol 2014;176:724-30.

6. Hernandez AF, Fonarow GC, Liang L, et al. Sex and racial differences in the use of implantable cardioverter-defibrillators among patients hospitalized with heart failure. JAMA 2007;298:1525-32

7. Garg PP, Furth SL, Fivush BA, et al. Impact of gender on access to the renal transplant waiting list for pediatric and adult patients. $J \mathrm{Am}$ Soc Nephrol 2000;11:958-64.

8. Couchoud $\mathrm{C}$, Bayat $\mathrm{S}$, Villar $\mathrm{E}$, et al. A new approach for measuring gender disparity in access to renal transplantation waiting lists. Transplantation 2012;94:513-19.

9. Hawker GA, Wright JG, Coyte PC, et al. Differences between men and women in the rate of use of hip and knee arthroplasty. $N$ Engl J Med 2000;342:1016-22.

10. Aldea GS, Gaudiani JM, Shapira OM, et al. Effect of gender on postoperative outcomes and hospital stays after coronary artery bypass grafting. Ann Thorac Surg 1999;67:1097-103.

11. Koch CG, Weng YS, Zhou SX, et al. Prevalence of risk factors, and not gender per se, determines short- and long-term survival after coronary artery bypass surgery. J Cardiothorac Vasc Anesth 2003;17:585-93.

12. Rogers MA, Blumberg N, Heal JM, et al. Increased risk of infection and mortality in women after cardiac surgery related to allogeneic blood transfusion. J Womens Health (Larchmt) 2007;16:1412-20.

13. Ried M, Lunz D, Kobuch $R$, et al Gender's impact on outcome in coronary surgery with minimized extracorporeal circulation. Clin Res Cardiol 2012;101:437-44.

14. Othman $\mathrm{H}$, Khambatta $\mathrm{S}$, Seth $\mathrm{M}$, et al. Differences in sex-related bleeding and outcomes after percutaneous coronary intervention: insights from the Blue Cross Blue Shield of Michigan Cardiovascula Consortium (BMC2) registry. Am Heart J 2014;168:552-9.

15. Yu J, Mehran R, Grinfeld L, et al. Sex-based differences in bleeding and long term adverse events after percutaneous coronary intervention for acute myocardial infarction: three year results from the HORIZONS-AMI trial. Catheter Cardiovasc Interv 2015:85:359-68.

16. Stehling L. Gender-related variation in transfusion practices. Transfusion 1998;38:392-9.

17. Rogers MA, Blumberg N, Saint SK, et al. Allogeneic blood transfusions explain increased mortality in women after coronary artery bypass graft surgery. Am Heart J 2006;152:1028-34.

18. Ranucci M, Pazzaglia A, Bianchini C, et al. Body size, gender, and transfusions as determinants of outcome after coronary operations. Ann Thorac Surg 2008;85:481-6.

19. Desai SJ, Wood KS, Marsh J, et al. Factors affecting transfusion requirement after hip fracture: can we reduce the need for blood? Can J Surg 2014:57:342-8.

20. Gombotz H, Rehak PH, Shander A, et al. The second Austrian benchmark study for blood use in elective surgery: results and practice change. Transfusion 2014;54(Pt 2):2646-57.

21. Gombotz H, Rehak $\mathrm{PH}$, Shander $\mathrm{A}$, et al. Blood use in elective surgery: the Austrian benchmark study. Transfusion 2007; 47:1468-80.

22. Gombotz H, Zacharowski K, Spahn D. Patient blood management Stuttgart, New York, Delhi, Rio de Janeiro: Thieme, 2016.

23. Shander A, Isbister J, Gombotz H. Patient blood management: the global view. Transfusion 2016;56(Suppl 1):S94-102.
24. Ranucci M, Baryshnikova E, Castelvecchio S, et al. Major bleeding, transfusions, and anemia: the deadly triad of cardiac surgery. Ann Thorac Surg 2013;96:478-85.

25. World Health Organization. Nutritional anaemias. Report of a WHO Scientific Group. Technical Report Series, 1968;405.

26. Du Bois D, Du Bois EF. A formula to estimate the approximate surface area if height and weight be known. 1916. Nutrition 1989;5:303-11; discussion 12-3.

27. Nadler SB, Hidalgo JH, Bloch T. Prediction of blood volume in normal human adults. Surgery 1962;51:224-32.

28. Chaplin $\mathrm{H}$ Jr, Mollison PL, Vetter H. The body/venous hematocrit ratio: its constancy over a wide hematocrit range. J Clin Invest 1953;32:1309-16.

29. Serrick CJ, Scholz M, Melo A, et al. Quality of red blood cells using autotransfusion devices: a comparative analysis. J Extra Corpor Technol 2003;35:28-34.

30. Loor G, Rajeswaran J, Li L, et al. The least of 3 evils: exposure to red blood cell transfusion, anemia, or both? J Thorac Cardiovasc Surg 2013;146:1480-7.e6.

31. Gupta PK, Sundaram A, Mactaggart JN, et al. Preoperative anemia is an independent predictor of postoperative mortality and adverse cardiac events in elderly patients undergoing elective vascular operations. Ann Surg 2013;258:1096-102.

32. Ad N, Holmes SD, Massimiano PS, et al. Operative risk and preoperative hematocrit in bypass graft surgery: role of gender and blood transfusion. Cardiovasc Revasc Med 2015;16:397-400.

33. Spiegelstein D, Holmes SD, Pritchard G, et al. Preoperative hematocrit as a predictor of perioperative morbidities following nonemergent coronary artery bypass surgery. J Card Surg 2015;30:20-6.

34. Hollis RH, Singletary BA, McMurtrie JT, et al. Blood transfusion and 30-day mortality in patients with coronary artery disease and anemia following noncardiac surgery. JAMA Surg 2016;151:139-45.

35. von Heymann C, Kaufner L, Sander M, et al. Does the severity of preoperative anemia or blood transfusion have a stronger impact on long-term survival after cardiac surgery? J Thorac Cardiovasc Surg 2016;152:1412-20.

36. Engoren M, Schwann TA, Habib $\mathrm{RH}$, et al. The independent effects of anemia and transfusion on mortality after coronary artery bypass. Ann Thorac Surg 2014;97:514-20.

37. Hearnshaw SA, Logan RF, Palmer KR, et al. Outcomes following early red blood cell transfusion in acute upper gastrointestinal bleeding. Aliment Pharmacol Ther 2010;32:215-24.

38. Jairath V, Hearnshaw S, Brunskill SJ, et al. Red cell transfusion for the management of upper gastrointestinal haemorrhage. Cochrane Database Syst Rev 2010;Cd006613.

39. Restellini S, Kherad O, Jairath V, et al. Red blood cell transfusion is associated with increased rebleeding in patients with nonvariceal upper gastrointestinal bleeding. Aliment Pharmacol Ther 2013;37:316-22.

40. Valeri CR, Cassidy G, Pivacek LE, et al. Anemia-induced increase in the bleeding time: implications for treatment of nonsurgical blood loss. Transfusion 2001;41:977-83.

41. Shander A, Hofmann A, Isbister J, et al. Patient blood management -the new frontier. Best Pract Res Clin Anaesthesiol 2013;27:5-10.

42. Meier J, Gombotz H. Pillar III-optimisation of anaemia tolerance. Best Pract Res Clin Anaesthesiol 2013;27:111-19.

43. Izaks GJ, Westendorp RG, Knook DL. The definition of anemia in older persons. JAMA 1999:281:1714-17.

44. Chaves $\mathrm{PH}$, Xue QL, Guralnik JM, et al. What constitutes norma hemoglobin concentration in community-dwelling disabled older women? J Am Geriatr Soc 2004:52:1811-16.

45. Culleton BF, Manns BJ, Zhang J, et al. Impact of anemia on hospitalization and mortality in older adults. Blood 2006;107:3841-6.

46. Martinsson A, Andersson $C$, Andell $P$, et al. Anemia in the general population: prevalence, clinical correlates and prognostic impact. Eur J Epidemiol 2014;29:489-98.

47. Endres HG, Wedding U, Pittrow D, et al. Prevalence of anemia in elderly patients in primary care: impact on 5-year mortality risk and differences between men and women. Curr Med Res Opin 2009;25:1143-58.

48. Anía BJ, Suman VJ, Fairbanks VF, et al. Prevalence of anemia in medical practice: community versus referral patients. Mayo Clin Proc 1994;69:730-5.

49. Anía BJ, Suman VJ, Fairbanks VF, et al. Incidence of anemia in older people: an epidemiologic study in a well defined population. J Am Geriatr Soc 1997:45:825-31.

50. Guralnik JM, Eisenstaedt RS, Ferrucci L, et al. Prevalence of anemia in persons 65 years and older in the United States: evidence for a high rate of unexplained anemia. Blood 2004;104:2263-8.

51. Tang YD, Katz SD. Anemia in chronic heart failure: prevalence etiology, clinical correlates, and treatment options. Circulation 2006;113:2454-61. 
52. Zarychanski R, Houston DS. Anemia of chronic disease: a harmful disorder or an adaptive, beneficial response? CMAJ 2008;179:333-7.

53. Maurer MS, Teruya S, Chakraborty B, et al. Treating anemia in older adults with heart failure with a preserved ejection fraction with epoetin alfa: single-blind randomized clinical trial of safety and efficacy. Circ Heart Fail 2013:6:254-63.

54. Na HS, Shin SY, Hwang JY, et al. Effects of intravenous iron combined with low-dose recombinant human erythropoietin on transfusion requirements in iron-deficient patients undergoing bilateral total knee replacement arthroplasty. Transfusion 2011;51:118-24.

55. Goodnough LT, Maniatis A, Earnshaw P, et al. Detection, evaluation, and management of preoperative anaemia in the elective orthopaedic surgical patient: NATA guidelines. $\mathrm{Br} J$ Anaesth 2011:106:13-22.

56. Karkouti K, Wijeysundera DN, Yau TM, et al. The influence of baseline hemoglobin concentration on tolerance of anemia in cardiac surgery. Transfusion 2008;48:666-72.

57. Hogervorst E, Rosseel P, van der Bom J, et al. Tolerance of intraoperative hemoglobin decrease during cardiac surgery. Transfusion 2014:54(Pt 2):2696-704.

58. American Society of Anesthesiologists Task Force on Perioperative Blood Management. Practice guidelines for perioperative blood management: an updated report by the American society of Anesthesiologists task force on perioperative blood management. Anesthesiology 2015;122:241-75.

59. Napolitano LM, Kurek S, Luchette FA, et al. Clinical practice guideline: red blood cell transfusion in adult trauma and critical care. Crit Care Med 2009;37:3124-57.

60. Beutler E, Waalen J. The definition of anemia: what is the lower limi of normal of the blood hemoglobin concentration? Blood 2006;107:1747-50.
61. Patel KV. Epidemiology of anemia in older adults. Semin Hematol 2008:45:210-17.

62. American Society of Anesthesiologists Task Force on Perioperative Blood Transfusion and Adjuvant Therapies. Practice guidelines for perioperative blood transfusion and adjuvant therapies: an updated report by the American Society of Anesthesiologists Task Force on Perioperative Blood Transfusion and Adjuvant Therapies. Anesthesiology 2006;105:198-208

63. Ferraris VA, Brown JR, Despotis GJ, et al., Society of Thoracic Surgeons Blood Conservation Guideline Task Force. 2011 update to the society of thoracic surgeons and the society of cardiovascular anesthesiologists blood conservation clinical practice guidelines. Ann Thorac Surg 2011;91:944-82.

64. Carson JL, Grossman BJ, Kleinman S, et al. Red blood cell transfusion: a clinical practice guideline from the AABB. Ann Intern Med 2012;157:49-58.

65. Meier J, Filipescu D, Kozek-Langenecker S, et al., ETPOS collaborators. Intraoperative transfusion practices in Europe. Br J Anaesth 2016;116:255-61.

66. Holst LB, Haase N, Wetterslev J, et al., TRISS Trial Group Scandinavian Critical Care Trials Group. Lower versus higher hemoglobin threshold for transfusion in septic shock. N Engl J Med 2014;371:1381-91.

67. Carson JL, Brooks MM, Abbott JD, et al. Liberal versus restrictive transfusion thresholds for patients with symptomatic coronary artery disease. Am Heart J 2013;165:964-71.

68. Rohde JM, Dimcheff DE, Blumberg N, et al. Health care-associated infection after red blood cell transfusion: a systematic review and meta-analysis. JAMA 2014;311:1317-26.

69. Salpeter SR, Buckley JS, Chatterjee S. Impact of more restrictive blood transfusion strategies on clinical outcomes: a meta-analysis and systematic review. Am J Med 2014;127:124-31.e3. 